\title{
On Thinking and STEM Education
}

Check for updates

\section{Yeping $\mathrm{Li}^{1}$ • Alan H. Schoenfeld ${ }^{2}$. Andrea A. diSessa ${ }^{2}$ - Arthur C. Graesser ${ }^{3}$ • Lisa C. Benson ${ }^{4} \cdot$ Lyn D. English ${ }^{5} \cdot$ Richard A. Duschl $^{6}$}

Published online: 27 February 2019

(C) Springer Nature Switzerland AG 2019

\section{Abstract}

The rapidly evolving and global field of STEM education has placed everincreasing calls for interdisciplinary research and the development of new and deeper scholarship in and for STEM education. In this editorial, we focus on the topic of thinking, first with a brief overview of related studies and conceptions in the past. We then problematize a traditional conception of thinking in the context of STEM education, and propose possible alternative perspectives about thinking areas for future research.

Keywords Thinking $\cdot$ Models of thinking $\cdot$ STEM education $\cdot$ STEM integration $\cdot$ STEM thinking

\section{Yeping Li}

yepingli@tamu.edu

Alan H. Schoenfeld alans@berkeley.edu

Andrea A. diSessa disessa@berkeley.edu

Arthur C. Graesser graesser@memphis.edu

Lisa C. Benson

lbenson@clemson.edu

Lyn D. English

1.english@qut.edu.au

Richard A. Duschl

rduschl@smu.edu

Extended author information available on the last page of the article 


\section{Introduction}

Mathematics (M) and science (S) have long been important in K-16 education internationally. For example, the International Association for the Evaluation of Educational Achievement (IEA) identified mathematics and science as important school subjects when investigating the outcomes of various school systems around the world. IEA conducted the First International Mathematics Study in 12 participating countries in 1964 (Husén 1967) and the First International Science Study, focusing on biology, chemistry, and physics, in 19 participating countries in 1970-1971 (Comber and Keeves 1973). While efforts to add or change a school subject or course are not new in the history of K-16 education, it is fascinating for us to witness and wonder: What makes the adding of technology (T) and engineering (E) in education so special nowadays, while still maintaining the importance of $\mathrm{M}$ and $\mathrm{S}$ ? What can and should we expect students to learn differently with the adding of $T$ and $E$ ? What makes the combination of $\mathrm{T}$ and $\mathrm{E}$ with $\mathrm{M}$ and $\mathrm{S}$ something special for students' learning of knowledge and thinking development? Clearly, we have many more questions than answers in science, technology, engineering, and mathematics (STEM) education.

Coining the acronym of STEM itself is not enough to justify why STEM education has drawn so much attention internationally over the past decade. The importance of STEM education has been recognized for preparing diverse students for growing job opportunities in STEM in the future, and to a nation as a whole for technological innovations and national prosperity and security (e.g., Committee on STEM Education 2018; National Academies of Sciences, Engineering, and Medicine 2007; National Science Foundation 2010; U.S. Department of Education 2016). At the same time, however, there are on-going doubts and critiques of the obsession with STEM education as being delusive and unrelated to human concerns, and which will not bring changes desired in school education (e.g., Hacker 2016; Zakaria 2015). In spite of such doubts and critiques, to many educators and policy makers internationally, STEM education brings hope for changes in education that will benefit all students, now and in the future, and they also look for new and robust scholarship to support such changes (Li 2018a).

Developing scholarship in STEM education is not a small task, as it requires team and community work, cross-disciplinary collaboration, and long-term dedication. With such understanding, members of this journal's editorial board are invited to collaborate to raise questions and perspectives that can reflect and promote the rapid development of integrated STEM education around the globe. In particular, we use the journal's editorial form of contribution, occasional guest editorials, as a platform to initiate, develop, and encourage interdisciplinary discussion and research in and for STEM education. By doing so, we do not wish to limit discussions and research to only those issues or topics raised in the editorials. While there are many important topics and issues related to STEM education, especially integrated STEM education, that remain to be explored, these editorials can help illustrate which themes, topics, or issues might be relevant to this journal.

In this editorial, we start with the topic of "thinking," in general, not simply because it is a common focus in education, but because, we argue, it becomes especially valuable for students to develop in and through STEM education. In the following sections, we provide a brief overview of conceptions and studies about thinking and share our questions and alternative perspectives about how thinking can be conceptualized. In particular, we propose that thinking needs to be reconceptualized in and for 
STEM education, rather than to be viewed only as a single individual-based cognitive process, as in traditional studies in psychology. We develop one possible alternative perspective about thinking as plural, in which thinking can be differentiated into multiple models with levels. With this perspective, we further argue that integrated STEM education is uniquely positioned to offer our students ample opportunities to develop multiple models of thinking productively.

\section{Reviewing Conceptions and Studies of Thinking}

Thinking is what we do every day, with various forms and functions. Over a century, scholars have been fascinating about the topic of thinking, and developed many innovative approaches and theoretical perspectives to conceptualize and study thinking. The scholarship about thinking, predominantly as situated in individual's mind, has shown its development from philosophical discussion to psychological studies in and across disciplinary domains. Here we briefly review and summarize some of them that bear close connections with STEM.

\section{Thinking Viewed from a Philosophical Perspective}

One of America's foremost philosophers and educators, John Dewey, tackled the topic of thought from a philosophical perspective in his classic book How We Think (Dewey 1910). Viewing thought and thinking as interchangeable, he shared his views on questions such as, What is thought? Can thought be trained? and What natural resources can be used in the training of thought? He offered philosophical guidance for teachers through analyses of topics such as rational thought, scientific inquiry, the processes of inductive and deductive reasoning, and the teacher-student relationship. His detailed analyses of inductive and deductive thought as the double movement of reflection show important features of logical reasoning that are applicable to various settings such as, doing scientific experiments and a physician making his diagnosis. Although his philosophical discussion is still as inspirational to educators today as in the past, his conceptualization of thinking as what occurred in individual's mind that can't be directly observed or perceived limited him to discuss thinking in general terms rather than as an empirical and systematic study.

\section{Thinking Viewed as Cognitive Processes and Strategies in Individual Problem Solving Activities}

Conceptualizing thinking as individual's cognitive processes and strategies has long been important in cognitive psychology. Revolutionary changes in studying problem solving occurred when the information processing approach was introduced in the 1950s and 1960s (e.g., Hovland 1952; Hunt 1962; as cited in Simon 1979). Benefitting from the development of computer technology, psychologists were able to use computers to simulate human's problem solving performance (Newell and Simon 1972). Supported by empirical evidence from both human problem solving performance and computer simulation, the information processing process in computers was used to conceptualize information processing process in human's mind, with structural 
components of short-term memory, long-term memory and associated mechanisms similar to what are constructed in computers. Although Newell and Simon's Human Problem Solving (1972) framed a general theory of human cognition beyond problem solving, thinking was mainly taken and studied as problem solving in their seminal book.

Simon expanded the information processing model of "problem solving man" from Newell and Simon (1972) to the notion of "thinking man" in the book Models of Thought (Simon 1979), a collection of journal articles with many of them that Simon collaboratively wrote with others including psychologists and computer scientists; a second volume was published 10 years later (Simon 1989). With the notion of "thinking man", Simon was able to compile various studies associated with thinking to include a wide range of task domains such as learning and remembering, problem solving, inducing rules, attaining concepts, and understanding natural language, that can be viewed as models of thought for the thinking man in each of these domains. Simon conceptualized and modeled the thinking man's information processing as containing different components that can and should be merged into a coherent whole (Simon 1979). Thus, human's thinking is fundamentally conceptualized and modeled as a general and coherent cognitive process with different components in individual's mind.

Although rooted in the computer simulation of human cognition many years ago, the notion of quantifying information for processing in human mind, as happens in computers, is indeed powerful and still has its great influence nowadays. Jeannette M. Wing at Carnegie Mellon University, where the information processing theory of human cognition was mainly developed, published a succinct article in arguing that computational thinking "represents a universally applicable attitude and skill set everyone, not just computer scientists, would be eager to learn and use" (Wing 2006, p. 33). The article has drawn widespread interest and prompted discussions about computational thinking as critical to all modern STEM disciplines (e.g., Henderson et al. 2007) and its status in K-12 education (e.g., Grover and Pea 2013). Questions are also raised to further clarify computational thinking (e.g., diSessa 2018; Grover and Pea 2013) and a possible important alternative, computational literacy, is also proposed to enrich the meaning of computational thinking (e.g., diSessa 2018). In a nutshell, computational literacy avoids Wing's claim that the importance of computation lies in powerful, general skills that can be developed by using computers. Rather, computation can change the very intellectual landscape of particular domains, in the same way that Arabic notation completely changed the doing of "arithmetic," and who could do it, and algebra and calculus transformed the study of physics from a philosophical inquiry to a rigorous, precise empirical pursuit (diSessa, 2000). More broadly, such scholarly developments and reports suggest the importance of paying close attention to computational thinking and related notions in STEM education and developing further research in the future.

It is important to point out that research on individual students' thinking goes beyond the conceptualization of thinking to designing and empirical testing, as illustrated in the research work using the information processing approach discussed above. In addition, researchers also used other methods such as instructional experiments to study individual students' attainment and development of thinking skills (e.g., Chipman et al. 1985; Segal et al. 1985). Conceptualizing and studying thinking as supported with experimental studies and empirical analyses mark the scholarship development on thinking from the past, both theoretically and methodologically. 
The above conceptions and modeling of thinking have been influential, while focusing on individual's mind as an independent entity. However, thinking and learning often take place in a group setting, both in the context of K-16 STEM education and the workplace (Autor et al. 2003; Fiore et al. 2018). What important differences in thinking and skill requirement and development emerge when we consider that students do not sit alone but work and discuss with others in situations such as collaborative problem solving (e.g., Graesser et al. 2018), and in classroom discourse and argumentation (e.g., Duschl and Osborne 2002). As an example, Graesser and his colleagues argue that collaborative problem solving (CPS) requires a set of cognitive and social skills that are different from traditional studies on an individual's problem solving (Graesser et al. 2018). This unique set of cognitive and social skills can include:

- Shared understanding: Group members share common goals when solving a new problem.

- Accountability: The contributions that each member makes are visible to the rest of the group.

- Differentiated roles: Group members draw on their specific expertise to complete different tasks.

- Interdependency: Group members depend on the contributions of others to solve the problem.

Graesser and his colleagues further indicate that current school curricula and instruction typically focus on task- and discipline-specific knowledge, placing little emphasis on promoting students' ability to communicate and collaborate effectively (Fiore et al. 2018; Graesser et al. 2018). This point is consistent with the potential opportunities that STEM education provides for students to participate in group activities with meaningful instruction, modeling, and feedback on collaborations. Graesser et al.'s work that identifies the essential cognitive and social components of CPS goes beyond traditional conceptualizations and models of thinking as individual-based cognitive processes.

\section{Thinking Viewed as Discipline-Based Individual Cognitive Endeavor}

There are many scholars outside of psychology who have also studied thinking from their unique vantage points such as mathematicians, scientists, and educators. George Pólya, a mathematician at Stanford University, published How to Solve It (1945) that provides general heuristics for solving a wide range of problems, both mathematical and non-mathematical. In this book, thinking is conceptualized as problem solving with heuristics (or strategies) as techniques. Different from psychological studies of problem solving that provide a theoretical understanding of cognitive processes, Pólya tends to provide practical suggestions to teachers of mathematics. His book presents a mathematical approach to study problem solving.

Problem solving was highly emphasized in mathematics education in the 1980s, when it was proposed as the core of school mathematics in the United States (National Council of Teachers of Mathematics 1980). Research efforts were also focused on the study of mathematical problem solving. For example, Schoenfeld built upon Pólya's work in his book Mathematical Problem Solving (1985), developing a framework that includes four categories of problem solving skills: knowledge base, heuristics, 
monitoring and self-regulation, and beliefs. His framework for analyzing problem solving indicates that knowing heuristics alone is not enough to guarantee problem solving success. Schoenfeld supported his framework with experiments and detailed data analyses that illustrate how Pólya's heuristics can become practically useful for different students. While discipline-based (or disciplinary domain-specific) knowledge is essential in mathematical problem solving, the thinking skills highlighted in Schoenfeld's framework actually include both disciplinary domain-specific and domain-general components. The inclusion of both domain-specific and domaingeneral components is consistent with what the national and international assessments of problem solving, such as the Programme for International Student Assessment (PISA), have used and revealed (Greiff et al. 2014).

Building on his work on mathematical problem solving, Schoenfeld studied teaching mathematics with a focus on how teachers make decisions during classroom interactions (Schoenfeld 2011). He developed a theory of decision making that describes how teachers, and individuals more generally, navigate their way through in-the-moment decision-making in their familiar domains. Instead of viewing thinking as individual's internal cognitive process, Schoenfeld's work, consistent with his work on mathematical problem solving, highlights how resources (especially their prior knowledge and the tools at their disposal), orientations (a generalization of beliefs, including values and preferences), and goals (often being chosen on the basis of their orientations and available resources) function together, beyond an individual's cognitive processes, in virtually all knowledge-rich domains (Schoenfeld 2014). Such an expanded notion of what research reveals about thinking and its contributing factors may further include one's history, available external resources, non-cognitive characteristics, and environmental and cultural factors, as what research has revealed about learning nowadays (National Research Council 2018).

Studies on thinking in discipline-based education are needed to provide theoretical perspectives and guidance for teaching and learning in different disciplines. Many types of thinking have been identified and studied as pertinent to certain disciplines, but less so to other disciplines. For example, a broadened perspective on mathematics and mathematical reasoning views reasoning as "embodied" and "imaginative", rather than only in the traditional sense as "abstract" and "disembodied" (e.g., English 1997; Lakoff and Núñez 2000). In the book edited by English (1997), Mathematical Reasoning, this perspective allows the book's contributors to discuss how students' physical experiences with concrete and visual materials can be transformed into models for abstract thought, along with the role of "thinking tools," such as analogy, metaphor, and image, in mathematical reasoning. At the same time, multiple approaches are often developed and used in studying discipline-based thinking such as, mathematical thinking. Sternberg and Ben-Zeev (1996) demonstrated in their edited book, Nature of Mathematical Thinking, that studies about mathematical thinking can take a range of different approaches including, psychometric approach, cognitive informationprocessing approach, cognitive-cultural approach, cognitive-educational approach, and mathematical approach. From a practice perspective, although mathematical thinking, especially inductive and deductive reasoning, is often taken as commonly needed in different STEM disciplines, improving students' mathematical thinking is traditionally left for educators and teachers in mathematics. It is thus not surprising if disciplinebased educators and teachers are hardly communicated to each other about developing 
students' thinking. One possible factor is that discipline-based thinking has traditionally emphasized the importance of a specific discipline (e.g., mathematics) but made other cognitive components almost invisible, which does not follow what Schoenfeld's problem solving framework tends to reveal.

Discipline-based approaches can be found with research on thinking in other STEM disciplines. For example, design thinking is often associated with innovation (e.g., Leavy 2010), and engineering is viewed as the driving force behind design thinking (Simon 1996). Although design thinking is important for students in the twenty-first century (Razzouk and Shute 2012), it is not a type of thinking skills that traditional mathematics and science educators would address, leaving a void in school education in terms of preparing students to be innovative and successful in today's highly competitive world. At the same time, the emphasis on the disciplinary aspect of design thinking tends to place engineering as the only discipline responsible for developing students' design thinking. Although engineering design has received substantial attention in recent years as an essential component in STEM education (e.g., McFadden and Roehrig 2018; Park et al. 2018; Strimel et al. 2018), much more research is needed to explore possible ways of integrating design thinking in school education, especially through STEM education.

As further examples, critical thinking and creativity are another two types of cognitive competences that are discussed broadly in literature and education (e.g., Lai 2011; Loveless 2002; Sternberg 1999; Tiwari et al. 2006), and to a certain degree in school science and mathematics education (e.g., Bailin 2002; Kind and Kind 2007; Silver 1997). Similar to design thinking, both critical thinking and creativity are highly valued in education and identified as important cognitive competences for students in the twenty-first century (Pellegrino and Hilton 2012). Different from design thinking, they are perceived as more of domain-general cognitive competences. Specifically, background knowledge is perceived as a necessary but not a sufficient condition for enabling critical thinking within a given discipline. At the same time, it is debatable about the extent to which critical thinking is domain-specific (Lai 2011). The importance of creativity is commonly acknowledged and highly valued in STEM disciplines. But creativity is associated much more closely with the arts, including visual and literary arts, rather than viewing and examining what STEM may possibly do to foster students' creativity in school education. There are many questions that remain to be explored about critical thinking and creativity in STEM education. For example, how are critical thing and creativity different from, and/or connected to, each other? How are they different from, and/or overlap with, design thinking? How does a person integrate critical thinking and creativity in school education for students' thinking development, especially through STEM education? What differences would it bring to develop students' critical thinking and creativity through individual's activity vs. group's collaborative work? Further research is needed.

\section{Problematizing Thinking in and for STEM Education}

The above brief overview of conceptions and studies about thinking outlines related scholarship development in broad strokes. Clearly, scholarship over the past 100 years has developed diverse perspectives and approaches about thinking, even within the same discipline, such as in mathematical thinking. However, most of previous studies on 
thinking have been on individual's cognitive process in a lab setting, or based on specific disciplines. Scholarship in this area prompts two main questions. First, while disciplinary domain-specific thinking has its own unique value pertinent to a specific discipline, how do we conceptualize thinking in and for STEM education more broadly? Second, when students do not work alone but often collaborate and interact with others in STEM education, how to conceptualize thinking?

Prior work points to the need of reconceptualizing thinking in and for STEM education. Specifically, discipline-based thinking in previous studies tends to specify and highlight content-based approaches but not relationships with thinking in other disciplines. Different from traditional discipline-specific education acting in silos, STEM education is multi-disciplinary or even further interdisciplinary. Previous conceptions of domain-specific thinking can and should be problematized.

Moreover, the lack of attention to students' collaborative interactions makes the traditional conceptions about thinking questionable for STEM education. The emphasis on students' group collaborative work is to help them develop those skills important in the twenty-first century. Problems have become substantially more complex nowadays, so complex that a single person cannot provide a deep solution to each problem. Instead, there needs to be a team with different expertise and perspectives to organize and communicate so that sophisticated solutions evolve. Possible examples include medical treatment of a heart problem, and the improvement of water quality in a community. Therefore, researchers argue that students' group-based collaborative problem solving and discourse present a set of cognitive and social skills different from individual student's work (e.g., Duschl and Osborne 2002; Graesser et al. 2018). STEM education is indeed conducive to activities that are student group's collaboration in nature as situated in a specific socio-cultural environment.

\section{Is there STEM Thinking? If Yes, how Should it Be Defined and Characterized?}

Studies on thinking have evolved over the years with a tendency from domain-general to domain-specific, a trend that is also shown in studies about learning from general models to discipline-specific learning trajectories (e.g., Greene et al. 2016). At the same time, however, domain-specific thinking and domain-general thinking are not dichotomous, as thinking itself is a complex process involving many different components. Domaingeneral thinking is often derived from human's thinking performance across different knowledge-lean (e.g., solving a puzzle) or -rich task domains (e.g., solving algebraic equations). Domain-specific thinking is often characterized in terms of its disciplinary content but also involves more general cognitive components. In other words, domainspecific thinking should contain both domain-specific and -general aspects of cognitive activities. For example, a mathematician's thinking is scarcely only mathematics (the knowledge component). It can share possible common elements with a biologist's thinking (e.g., certain aspects of metacognition and meta-representation).

The same reasoning applies to students' thinking in specific disciplines. For example, as discussed above, Schoenfeld's problem-solving framework (Schoenfeld 1985) illustrates that some aspects of mathematical problem solving are largely disciplinespecific (e.g., the knowledge base), some heavily discipline-oriented (e.g., strategies and beliefs), some much like discipline domain-general (e.g., metacognition). In sum, there are many components of thinking that might be shared across STEM disciplines, 
which prompts the general issues of how much thinking is domain-specific, how much is domain-general, and how much in-between?

STEM is not a single domain, or discipline. However, when STEM education is developed and implemented as specific sets of activities, would it be possible to develop students' thinking through such activities that can be called STEM thinking? If yes, how should STEM thinking be defined and characterized as different from thinking in specific disciplines? If STEM thinking can be defined in a meaningful way, how much does it overlap with thinking in other individual disciplines, for example, mathematics?

At the same time, current literature shows that STEM education is loosely defined and open to different interpretations (Li 2018b). STEM education and research can refer to a collection of traditionally separated disciplines, or the integrations of selected disciplines (not necessarily all four disciplines in STEM) in specific ways. The diverse perspectives about STEM and STEM education would pose another challenge for characterizing STEM thinking and whether it can be meaningfully defined, studied, and assessed. Further research and discussion are needed if such a notion of STEM thinking remains as a viable possibility.

\section{How Should Thinking in Integrated STEM Education Be Reconceptualized, when Integration itself Is Also Subject to Variations?}

This journal aims to promote the development of interdisciplinary research, especially in integrated STEM education (Li 2018a). However, currently STEM integration itself is also subject to different perspectives (e.g., English 2016). In addition, integration can take place among two, three, or four disciplines in STEM. Nevertheless, one common feature is that integrated STEM education involves more than one discipline. Therefore, would it be better to conceptualize thinking in integrated STEM activities as plural, rather than a singular model (e.g., mathematical reasoning) that is pertinent to a specific discipline?

Viewing thinking as plural differs from viewing thinking as containing different components. Traditional views of thinking are dominated by a single individualbased cognitive process as a whole that contains several components, as illustrated in Simon's models of thought $(1979,1989)$. Instead, thinking in integrated STEM education can be better reconceptualized and differentiated into multiple models. Individual models can be identified and developed as pertinent to thinking that takes place either in individuals or in groups. Each model can also refer to discipline-general or discipline-based thinking that have been the focus of previous studies such as mathematical reasoning, computational thinking, design thinking, and critical thinking. Individual models can be influenced and characterized further with respect to socio-cultural environments such as the language that students are accustomed to (National Research Council 2018). Furthermore, thinking can be differentiated into levels, similar to how diSessa (2015) defends studying knowledge according to different levels and Graesser and McNamara (2011) differentiate discourse comprehension into multiple levels. For each model of thinking, however, it is also important to clarify how levels of thinking are differentiated. For example, Simon (1979) indicates that thinking can be differentiated in terms of levels of information processing. Wing (2006) suggests that computational thinking can be differentiated at different levels of abstraction. 
The perspective of multiple models of thinking will not be apparent when students' thinking is focused on in a single discipline or when it is studied as individuals in a lab setting. The nature of integrated STEM education clearly differs from traditional discipline-based education, and it calls for the questioning and reconceptualizing of thinking as a process or activity that can be differentiated into multiple models and that can happen in individual's mind or in interactions among individuals. The perspective of multiple models of thinking suggests that students' learning can be amplified when specific models of thinking are specified and carefully assembled with a range of meaningful and appropriate materials, methods, and activities. If this perspective is meaningful and can be taken, it is clear that STEM education might be uniquely positioned to offer students opportunities to develop multiple models of thinking. Further discussion and development about this perspective are needed.

\section{Making Connections between Thinking Development through Integrated STEM Education and Twenty-First Century Skills}

The call for students to learn and develop twenty-first century skills has been on-going for years and around the world (e.g., Dede 2010; Trilling and Fadel 2012). Similar to the development of STEM education, the development of twenty-first century skills is driven by a need to prepare the workforce in today's highly competitive world (Trilling and Fadel 2012). For twenty-first century skills, there are also multiple frameworks being proposed such as Partnership for twenty-first Century Skills (P21), EnGauge Framework from Metiri/ NCREL, Organization for Economic Cooperation and Development (OECD) twenty-first century skills (Dede 2010). However, the specifications of twenty-first century skills vary across these frameworks.

To clarify the meaning of twenty-first century skills and "deep learning," a committee of the National Research Council of National Academies published a report, Education for Life and Work: Developing Transferable Knowledge and Skills in the twenty-first Century (Pellegrino and Hilton 2012). In this report, the committee identified three domains of competence: cognitive, interpersonal, and intrapersonal, while recognizing that these three domains represent distinct facets of human thinking and build on previous efforts to identify and organize dimensions of human behavior. The list of these three domains in the committee's report is aligned with the perspective of multiple models of thinking discussed above. The shared commonalities suggest that further discussion about these three domains of twenty-first century skills, multiple models of thinking, and STEM education should be on the research agenda in the future.

As STEM education is positioned to bring new perspectives and opportunities to school education, what students can and should learn and do in traditional schooling also need to be problematized and reconceptualized. With a focus on thinking, we hope that this editorial can stimulate more discussion and research about this topic in STEM education. What makes thinking especially important in education is that we not only want to understand how people think, but also try to find ways to develop students' thinking in new ways, respecting new conditions of the twenty-first century. Having uncovered many new questions, we would certainly like to continue our discussion about thinking. Stay tuned. 
Publisher's Note Springer Nature remains neutral with regard to jurisdictional claims in published maps and institutional affiliations.

\section{References}

Autor, D. H., Levy, F., \& Murnane, R. J. (2003). The skill content of recent technological change: An empirical exploration. Quarterly Journal of Economics, 118(4), 1279-1334.

Bailin, S. (2002). Critical thinking and science education. Science \& Education, 11(4), 361-375.

Chipman, S. F., Segal, J. W., \& Glaser, R. (1985). Thinking and learning skills. Volume 2: Research and open questions. New York: Routledge.

Comber, L. C., \& Keeves, J. P. (1973). Science education in nineteen countries: An empirical study. Stockholm: Almqvist \& Wiksell.

Committee on STEM Education, National Science \& Technology Council, the White House (2018). Charting a course for success: America's strategy for STEM education. Washington, DC. https://www.whitehouse. gov/wp-content/uploads/2018/12/STEM-Education-Strategic-Plan-2018.pdf Retrieved 18 January, 2019.

Dede, C. (2010). Comparing frameworks for $21^{\text {st }}$ century skills. In J. Bellanca \& R. Brandt (Eds.), 21st century skills: Rethinking how students learn (pp. 51-75). Bloomington: Solution Tree Press.

Dewey, J. (1910). How we think. Boston: D.C. Heath \& Co.

diSessa, A. A. (2000). Changing minds: Computers, learning, and literacy. Cambridge, MA: MIT Press.

diSessa, A. A. (2015). Commentary: How science is done. In A. A. diSessa, M. Levin, \& N. J. S. Brown (Eds.), Knowledge and interaction: A synthetic agenda for the learning sciences (pp. 525-550). New York: Routledge.

diSessa, A. A. (2018). Computational literacy and "the big picture" concerning computers in mathematics education. Mathematical Thinking and Learning, 20(1), 3-31. https://doi. org/10.1080/10986065.2018.1403544.

Duschl, R. A., \& Osborne, J. (2002). Supporting and promoting argumentation discourse in science education. Studies in Science Education, 38(1), 39-72. https://doi.org/10.1080/03057260208560187.

English, L. D. (Ed.). (1997). Mathematical reasoning: Analogies, metaphors, and images. New York: Routledge.

English, L. D. (2016). STEM education K-12: Perspectives on integration. International Journal of STEM Education, 3(3). https://doi.org/10.1186/s40594-016-0036-1.

Fiore, S. M., Graesser, A. C., \& Greiff, S. (2018). Collaborative problem solving education for the twentyfirst-century workforce. Nature Human Behavior, 2, 367-369.

Graesser, A. C., \& McNamara, D. S. (2011). Computational analyses of multilevel discourse comprehension. Topics in Cognitive Science, 3, 371-398.

Graesser, A. C., Fiore, S. M., Greiff, S., Andrews-Todd, J., Foltz, P. W., \& Hesse, F. W. (2018). Advancing the science of collaborative problem solving. Psychological Science in the Public Interest, 19(2), 59-92.

Greene, J. A., Sandoval, W. A., \& Bråten, I. (Eds.). (2016). Handbook of epistemic cognition. New York: Routledge.

Greiff, S., Wüstenberg, S., Csapó, B., Demetriou, A., Hautamäki, J., Graesser, A. C., \& Martin, R. (2014). Domaingeneral problem solving skills and education in the 21st century. Educational Research Review, 13, 74-83.

Grover, S., \& Pea, R. (2013). Computational thinking in K-12: A review of the state of the field. Educational Researcher, 42(1), 38-43.

Hacker, A. (2016). The math myth: And other STEM delusions. New York: The New Press.

Henderson, P. B., Cortina, T. J., Hazzan, O., and Wing, J. M. (2007). Computational thinking. In Proceedings of the 38th ACM SIGCSE Technical Symposium on Computer Science Education (SIGCSE '07), 195196. New York: ACM Press.

Hovland, C. I. (1952). A “communicational analysis” of concept learning. Psychological Review, 59, 461-472.

Hunt, E. B. (1962). Concept formation. New York: Wiley.

Husén, T. (Ed.). (1967). International study of achievement in mathematics: A comparison of twelve countries (Vol. 1-2). Stockholm: Almqvist \& Wiksell.

Kind, P. M., \& Kind, V. (2007). Creativity in science education: Perspectives and challenges for developing school science. Studies in Science Education, 43(1), 1-37.

Lai, E. R. (2011). Critical thinking: A literature review. Pearson's Research Report. http://images. pearsonassessments.com/images/tmrs/CriticalThinkingReviewFINAL.pdf Retrieved 2 February, 2019.

Lakoff, G., \& Núñez, R. (2000). Where mathematics come from: How the embodied mind brings mathematics into being. New York: Basic Books. 
Leavy, B. (2010). Design thinking - A new mental model of value innovation. Strategy \& Leadership, 38(3), 5-14. https://doi.org/10.1108/10878571011042050.

Li, Y. (2018a). Journal for STEM education research - Promoting the development of interdisciplinary research in STEM education. Journal for STEM Education Research, 1(1-2), 1-6. https://doi. org/10.1007/s41979-018-0009-z.

Li, Y. (2018b). Four years of development as a gathering place for international researchers and readers in STEM education. International Journal of STEM Education, 5(54). https://oi.org/10.1186/s40594-018-0153-0.

Loveless, A. M. (2002). Literature review in creativity, new technologies and learning. A NESTA Futurelab research report - report 4. https://telearn.archives-ouvertes.fr/hal-00190439/document Retrieved 2 February, 2019.

McFadden, J., \& Roehrig, G. (2018). Engineering design in the elementary science classroom: Supporting student discourse during an engineering design challenge. International Journal of Technology and Design Education. https://doi.org/10.1007/s10798-018-9444-5.

National Academies of Sciences, Engineering, and Medicine. (2007). Rising above the gathering storm: Energizing and employing America for a brighter economic future. Washington, DC: The National Academies Press.

National Council of Teachers of Mathematics. (1980). An agenda for action. Reston: The author.

National Research Council. (2018). How people learn II: Learners, contexts, and cultures. Washington, DC: National Academy Press.

National Science Foundation. (2010). Preparing the next generation of STEM innovators: Identifying and developing our nation's human capital. Arlington, Washington DC: the Author.

Newell, A., \& Simon, H. A. (1972). Human problem solving. Englewood Cliffs: Prentice-Hall.

Park, D.-Y., Park, M.-H., \& Bates, A. B. (2018). Exploring young children's understanding about the concept of volume through engineering design in a STEM activity: A case study. International Journal of Science and Mathematics Education, 16(2), 275-294.

Pellegrino, J. W., \& Hilton, M. L. (Eds.). (2012). Education for life and work: Developing transferable knowledge and skills in the 21st century. Washington, DC: The National Academies Press.

Pólya, G. (1945). How to solve it: A system of thinking which can help you solve any problem. Princeton: Princeton University Press.

Razzouk, R., \& Shute, V. (2012). What is design thinking and why is it important? Review of Educational Research, 82(3), 330-348.

Schoenfeld, A. H. (1985). Mathematical problem solving. Orlando: Academic Press.

Schoenfeld, A. H. (2011). How we think: A theory of goal-oriented decision making and its educational applications. New York: Routledge.

Schoenfeld, A. H. (2014). What makes for powerful classrooms, and how can we support teachers in creating them? A story of research and practice, productively intertwined. Educational Researcher, 43(8), 404412.

Segal, J. W., Chipman, S. F., \& Glaser, R. (1985). Thinking and learning skills. Volume 1: Relating instruction to research. New York: Routledge.

Silver, E. A. (1997). Fostering creativity through instruction rich in mathematical problem solving and problem posing. ZDM-The International Journal on Mathematics Education, 29, 75-80. https://doi. org/10.1007/s11858-997-0003-x.

Simon, H. A. (1979). Models of thought. Volume I. New Haven: Yale University Press.

Simon, H. A. (1989). Models of thought. Volume II. New Haven: Yale University Press.

Simon, H. A. (1996). The sciences of the artificial (3rd ed.). Cambridge: MIT Press.

Sternberg, R. J. (1999). Handbook of creativity. Cambridge: Cambridge University Press.

Sternberg, R. J., \& Ben-Zeev, T. (Eds.). (1996). The nature of mathematical thinking. New York: Routledge.

Strimel, G. J., Bartholomew, S. R., Kim, E., \& Zhang, L. (2018). An investigation of engineering design cognition and achievement in primary school. Journal for STEM Education Research, 1(1-2), 173-201.

Tiwari, A., Lai, P., So, M., \& Yuen, K. (2006). A comparison of the effects of problem-based learning and lecturing on the development of students' critical thinking. Medical Education, 40, 547-554.

Trilling, B., \& Fadel, C. (2012). $21^{\text {st }}$ century skills: Learning for life in our times. San Francisco: Jossey-Bass.

U.S. Department of Education (2016). STEM 2026: A vision for innovation in STEM education. https://innovation.ed.gov/files/2016/09/AIR-STEM2026_Report_2016.pdf Retrieved 18 January, 2019.

Wing, J. M. (2006). Computational thinking. Communications of the ACM, 49(3), 33-36.

Zakaria, F. (2015). Op-ed: Why America's obsession with STEM education is dangerous. The Washington Post, https://www.washingtonpost.com/opinions/why-stem-wont-make-us-successful/2015/03/26/5f4604 f2-d2a5-11e4-ab77-9646eea6a4c7_story.html?utm_term=.f500b2caa6e6 Retrieved 18 January, 2019. 


\section{Affiliations}

Yeping $\mathrm{Li}^{1}$ • Alan H. Schoenfeld ${ }^{2}$ - Andrea A. diSessa ${ }^{2}$ - Arthur C. Graesser ${ }^{3} \cdot$ Lisa C. Benson ${ }^{4} \cdot$ Lyn D. English ${ }^{5} \cdot$ Richard A. Duschl $^{6}$

1 Texas A\&M University, College Station, TX, USA

2 University of California-Berkeley, Berkeley, CA, USA

3 University of Memphis, Memphis, TN, USA

4 Clemson University, Clemson, SC, USA

5 Queensland University of Technology, Brisbane, Australia

6 Southern Methodist University, Dallas, TX, USA 